\title{
Computationally-Guided Development of a Chelated NHC-P Iridium(I) Complex for the Directed Hydrogen Isotope Exchange of Aryl Sulfones
}

William J. Kerr,* Gary J. Knox, Marc Reid, Tell Tuttle, Jonas Bergare, and Ryan A. Bragg

Cite This: ACS Catal. 2020, 10, 11120-11126

Read Online

ACCESS

亗 Metrics \& More

回国 Article Recommendations

Supporting Information

ABSTRACT: Herein, we report the rational, computationallyguided design of an iridium(I) catalyst system capable of enabling directed hydrogen isotope exchange (HIE) with the challenging sulfone directing group. Substrate binding energy was used as a parameter to guide rational ligand design via an in silico catalyst screen, resulting in a lead series of chelated iridium(I) NHCphosphine complexes. Subsequent preparative studies show that the optimal catalyst system displays high levels of activity in HIE, and we demonstrate the labeling of a broad scope of substituted aryl sulfones. We also show that the activity of the catalyst is

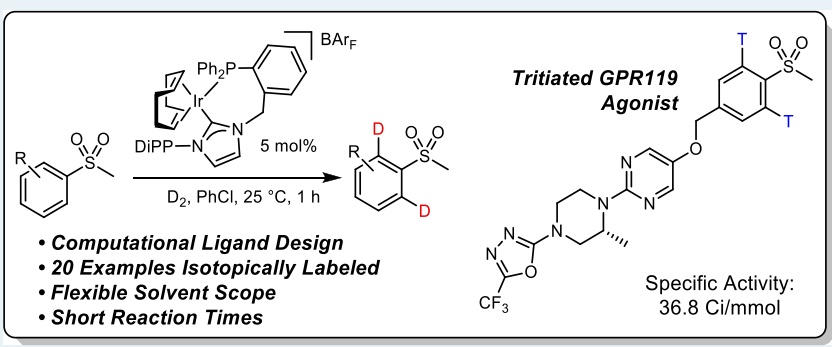
maintained at low pressures of deuterium gas and apply these conditions to tritium radiolabeling, including the expedient synthesis of a tritium-labeled drug molecule.

KEYWORDS: rational catalyst design, hydrogen isotope exchange, iridium catalysis, $\mathrm{C}-\mathrm{H}$ activation, sulfone

$\mathrm{T}$ he incorporation of heavy isotopes into potential drug molecules has, over time, become an indispensable tool within the pharmaceutical industry. ${ }^{1}$ One of the most utilized methods in this area is directed hydrogen isotope exchange (HIE, Scheme 1), wherein hydrogen atoms ortho to a Lewis basic directing group (DG) are replaced with deuterium or tritium. ${ }^{2}$

Scheme 1. General Reaction Scheme for Directed HIE

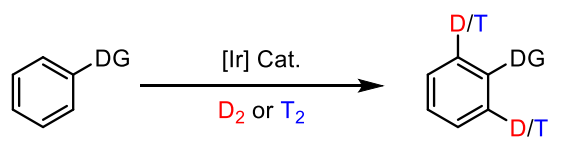

Homogeneous iridium catalysts have been proven to be highly active in ortho-directed HIE. ${ }^{3}$ These species have enabled the use of a broad range of directing groups in the labeling of small molecules and potential drug candidates. ${ }^{4}$ Related to this, studies within our own laboratory have led to the development of a series of catalytically active iridium(I) NHC/phosphine complexes 1-2 (Figure 1), which deliver heavy isotopes of hydrogen (deuterium, D and tritium, T) to aryl and alkenyl substrates via a directed $\mathrm{C}-\mathrm{H}$ activation process with a broad range of directing groups. ${ }^{3 \mathrm{~d}, 5}$ Additionally, iridium(I) NHC chloride complexes of type 3 have shown utility in the labeling of primary aryl sulfonamides and aryl aldehydes. $^{6}$

Despite these advances, however, certain high-value functionalities, common throughout pharmaceutical motifs

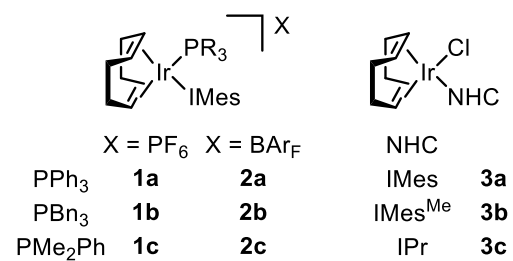

Figure 1. $\operatorname{Ir}(\mathrm{I})$ precatalysts for directed HIE.

and natural products, still present significant challenges for directed HIE. One such example is the aryl sulfone unit, which is prevalent throughout drug discovery. ${ }^{7}$ For example, sulfones are present in antibiotics, such as dapsone and dextrosulphenidol, ${ }^{8 a, b}$ and are also components within a range of other medicines, including the non-steroidal anti-inflammatory, rofecoxib, and the retinoid, sumarotene (Figure 2). ${ }^{8 c, d}$ However, the capacity to exploit the sulfone as a directing group in $\mathrm{C}-\mathrm{H}$ activation processes, ${ }^{9}$ including $\mathrm{HIE},{ }^{10}$ is currently vastly undermet. With specific regard to HIE, Pfaltz and Muri have reported an $N, P$-chelated $\operatorname{Ir}(\mathrm{I})$ catalyst, which mediates deuterium labeling of a series of substrates, including

Received: July 10, 2020

Revised: August 27, 2020

Published: September 1, 2020 
<smiles>Nc1ccc(S(=O)(=O)c2ccc(N)cc2)cc1</smiles><smiles>CS(=O)(=O)c1ccc([C@@H](O)[C@H](O)NC(=O)C(Cl)Cl)cc1</smiles><smiles>COc1ccccc1C1=C(c2ccc(S(C)(=O)=O)cc2)COC1=O</smiles>

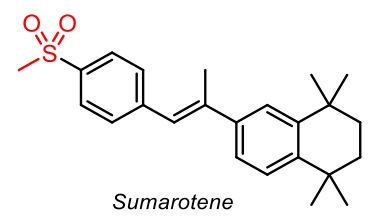

Figure 2. Examples of sulfone-containing drug molecules.

one example of a simple aryl (phenyl methyl) sulfone. This catalyst system does, however, require activation with elevated pressures $(2.2$ bar $)$ of deuterium. ${ }^{10 a}$ Nonetheless, the abundance of the sulfone moiety in pharmaceutically active agents makes the ability to exploit these functional units as handles for ortho-directed HIE a particularly attractive goal. Additionally, applying a mechanistic approach to such a challenge has the potential to deliver an enhanced, and potentially predictive, understanding of such directed functionalization endeavors, enabling the use of sulfones in a broader range of $\mathrm{C}-\mathrm{H}$ activation processes.

Current iridium-catalyzed HIE processes directed by sulfones have a range of limitations. For example, previous studies within our laboratory toward sulfone-directed HIE have employed monodentate iridium(I) catalysts, specifically NHC/ phosphine 1a and $\mathrm{NHC} / \mathrm{Cl}$ analogue 3a. When these catalyst systems were applied to the labeling of phenyl methyl sulfone 4a, low levels of incorporation were observed (Figure 3a). ${ }^{6 a}$ We hypothesized that, in this case, substrate binding was unusually the turnover-limiting step, in contrast to less hindered directing groups where $\mathrm{C}-\mathrm{H}$ activation is turnover limiting. ${ }^{5 c}$

Bearing in mind that catalysts $1-3$ possess very large NHC and (for 1 and 2) phosphine ligands, coordinated in a trans relationship (Figure $3 b$ ), the tetrahedral nature of the sulfone

a: Previous work

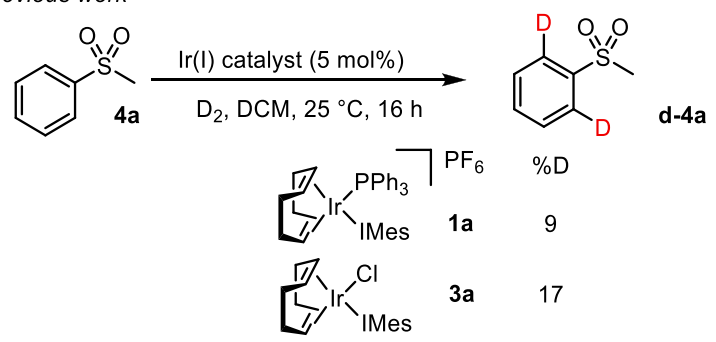

b: This work - solution to challenges in sulfone labeling

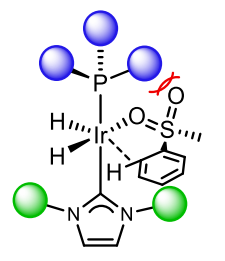

Monodentate NHC/Phosphine

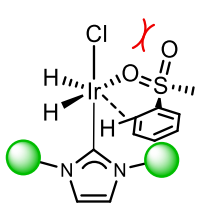

Monodentate $\mathrm{NHC} /$ Chloride

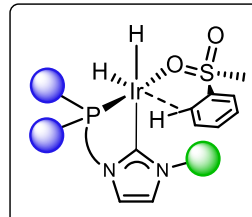

NHC-Phosphine Tethered Catalyst
Figure 3. Sulfone labeling: Challenges with monodentate catalysts and a potential chelated catalyst solution. directing group results in significant steric repulsion between the substrate and ligand when compared to more planar directing groups, such as acetyl. This may inhibit substrate binding, which in turn would severely limit the isotope incorporation in sulfone-derived substrates, as observed with 1a and $3 a^{6 a}$ We hypothesized that the use of a tethered $N$ heterocyclic carbene-phosphine ligand (NHC-P, Figure 3b) would result in a less hindered catalyst environment, more able to accommodate the sulfone unit.

The paradigm of rational ligand design is emerging as an appreciably powerful tool through which the knowledge and understanding gained from mechanistic insights allows an effective catalyst to be accessed rapidly. ${ }^{11,12}$ We selected this approach to address the challenge of developing a broadly effective chelated catalyst system with the ability to label sulfone-bearing substrates to high levels of isotope incorporation under mild reaction conditions. Specifically, a system derived from rational, computational design would not only provide a solution to the challenge of sulfone labeling but would also potentially facilitate the application of the designed system to a more diverse array of substrate classes.

To initiate our studies, and guided by our postulate that substrate binding was limiting in the sulfone case (Figure 3), computational modeling was used to calculate the binding energy $\left(E_{\text {Bind }}\right)$ of a model substrate methyl phenyl sulfone $\mathbf{4 a}$ to catalytically relevant ${ }^{5 c}$ iridium(III) hydride complexes of varying designs (Figure 4). The binding energy was calculated
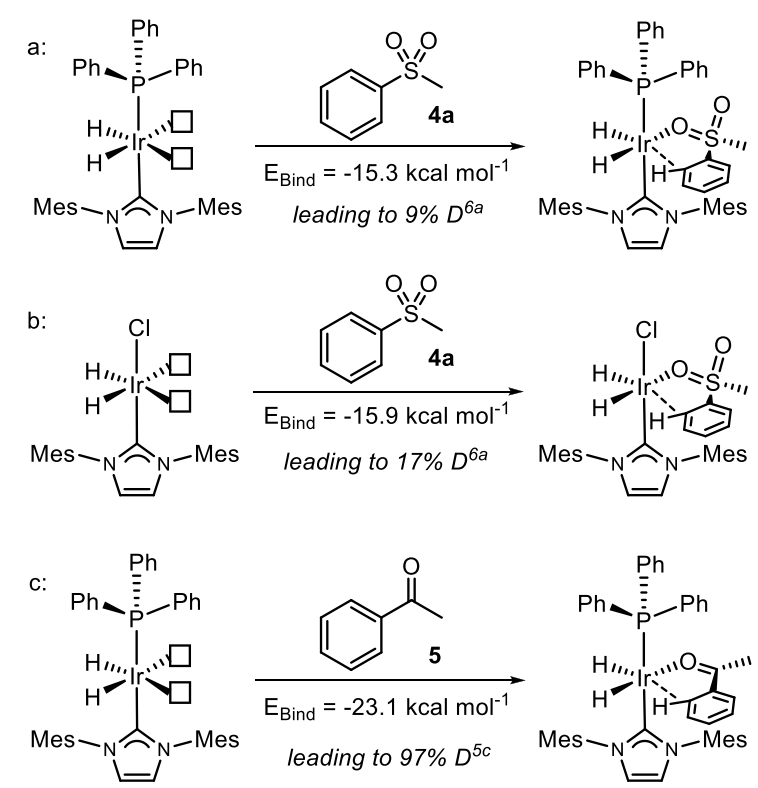

Figure 4. Calculation of binding energy with monodentate ligand systems.

using the counterpoise method, as described by Boys and Bernardi. ${ }^{13}$ We observed that while methyl phenyl sulfone $4 a$ could coordinate to the monodentate $\mathrm{NHC} /$ phosphine iridium(III) hydride derived from 1a (Figure 4a), a modest binding energy of only $-15.3 \mathrm{kcal} \mathrm{mol}^{-1}$ was calculated, with a similarly poor binding energy of $-15.9 \mathrm{kcal} \mathrm{mol}^{-1}$ for precatalyst 3a (Figure 4b). To place these binding energies in context, when the same method was applied to the binding of acetophenone $\mathbf{5}$ (which has been shown to label to high levels using precatalyst $1 \mathbf{a}^{5 \mathrm{c}}$ ), a significantly more negative and 
therefore more favorable binding energy of $-23.1 \mathrm{kcal} \mathrm{mol}^{-1}$ was found (Figure $4 c$ ).

In terms of selecting a chelating ligand system to overcome these binding issues, a number of tethered NHC-P ligand motifs have been reported. ${ }^{14}$ Due to the range of tethers and combinations of NHC and phosphine substituents already established, an in silico screening was carried out to determine which characteristics of the chelating ligand would lead to an increased sulfone binding energy, and thus a potentially effective catalyst system. Accordingly, we proposed a virtual library of eighteen structurally diverse NHC-P ligands, covering a number of chelate sizes (from four to seven membered rings), and a range of steric and electronic parameters, as dictated by the substituents on the NHC and phosphine moieties. In each case, the binding energy of methyl phenyl sulfone to the relevant chelated iridium(III) hydride was calculated (Scheme 2).

Scheme 2. In Silico Screen of Bidentate Ligands and the Calculated Binding Energy for Methyl Phenyl Sulfone
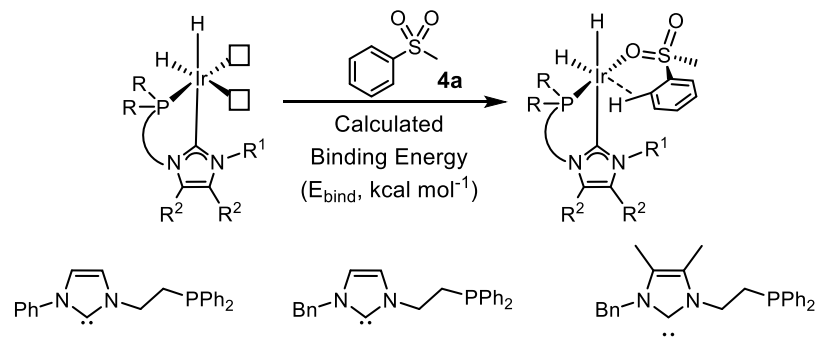

$6-24.9 \mathrm{kcal} \mathrm{mol}^{-1}$ $7-17.4 \mathrm{kcal} \mathrm{mol}{ }^{-1}$ $8-17.1 \mathrm{kcal} \mathrm{mol}^{-1}$
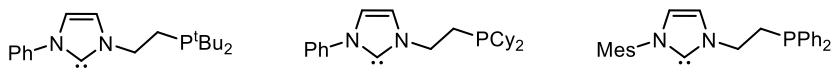

9 - $27.5 \mathrm{kcal} \mathrm{mol}^{-1}$

$10-29.5 \mathrm{kcal} \mathrm{mol}^{-1}$
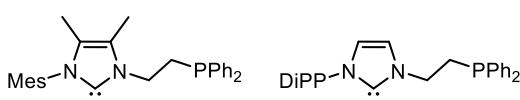

$12-27.8 \mathrm{kcal} \mathrm{mol}^{-1}$ $13-23.7 \mathrm{kcal} \mathrm{mol}^{-1}$

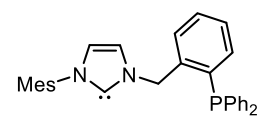

$15-27.4 \mathrm{kcal} \mathrm{mol}^{-1}$

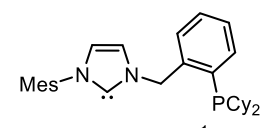

$16-22.8 \mathrm{kcal} \mathrm{mol}^{-1}$

$11-27.0 \mathrm{kcal} \mathrm{mol}^{-1}$
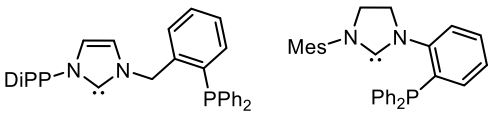

$19-27.4 \mathrm{kcal} \mathrm{mol}^{-1}$
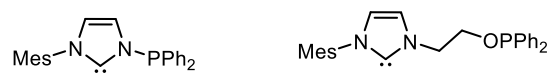

$21-27.1 \mathrm{kcal} \mathrm{mol}^{-1}$

$22-31.6 \mathrm{kcal} \mathrm{mol}^{-1}$

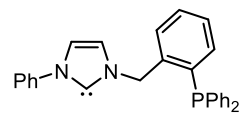

$14-24.1 \mathrm{kcal} \mathrm{mol}^{-1}$

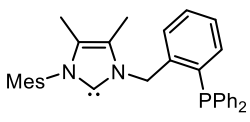

$17-28.6 \mathrm{kcal} \mathrm{mol}^{-1}$

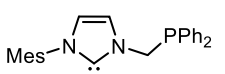

$20-27.9 \mathrm{kcal} \mathrm{mol}^{-1}$

Firstly, it was noted that only those ligands with $N$-aryl substituents gave significantly higher sulfone binding energies than the monodentate systems (cf. 6 vs 7 ). In general, ethylene tethered systems $(6,9-13)$ showed a favorable range of binding energies, from $-23.7 \mathrm{kcal} \mathrm{mol}^{-1}$ for $\mathbf{1 3}$ to $-29.5 \mathrm{kcal}$ $\mathrm{mol}^{-1}$ for 10. Also, aryl and alkyl phosphines both gave enhanced binding energies when compared to the aforementioned monodentate catalysts. Furthermore, substitution on the backbone of the NHC appeared to deliver a moderately more favorable binding energy in some cases (cf. 12 vs 11).
The larger, benzyl-tethered ligands, 14-18, also showed favorable sulfone binding energies with a similar pattern to the corresponding ethylene-bridged systems being observed in terms of the NHC substituent. Dicyclohexyl phosphinyl variant 16, however, displayed a reduced binding energy with respect to the diphenylphosphinyl analogue $\mathbf{1 5}$ and, as such, no further dialkylphosphines were considered. The effect of the chelate ring size and rigidity was next examined, with the orthophenylene, 19, methylene bridged, 20, and directly N-P bound ligand, 21, all displaying favorable binding energies. Interestingly, phosphite, 22, returned the highest binding energy of all ligand variations examined. Finally, the benzimidazole-derived NHC, 23, was also found to be favorable, resulting in a binding energy of $-30.8 \mathrm{kcal} \mathrm{mol}^{-1}$. The calculated binding energies for each of the 18 bidentate complexes, as well as monodentate complexes 1a and 3a, are shown graphically in Figure 5.

From this in silico screen, a total of six ligands $(11,13,15$, 17, 18, and 23) were selected for progression based on their binding energy of methyl phenyl sulfone $4 a$, coupled with their synthetic tractability in each case. The structures of the targeted iridium(I) precatalysts 24-29 are shown in Figure 6, with the selected ligands predicted to give complexes with a range of substrate binding energies from -23.7 to $-30.8 \mathrm{kcal}$ $\mathrm{mol}^{-1}$. The ligands for the iridium(I) precatalysts shown were then synthesized via modification of existing literature procedures. $^{14 \mathrm{~d}-\mathrm{g}, 15}$

With the iridium(I) precatalysts 24-29 in hand, their labeling of methyl phenyl sulfone $\mathbf{4 a}$ was investigated. This initial catalyst screen was performed at $25{ }^{\circ} \mathrm{C}$ in dichloromethane with a standard catalyst loading of $5 \mathrm{~mol} \%$ and a reaction time of $16 \mathrm{~h}$. In the majority of cases (i.e., with the exception of 25 and 27), a marked increase in the isotope incorporation was observed compared to the monodentate systems 1a and 3a (Table 1).

Based on the labeling results shown in Table 1 , the most promising catalyst, 29, was selected for further optimization, beginning with a solvent screen and exploiting the versatility of the catalyst's $\mathrm{BAr}_{\mathrm{F}}$ counterion in this regard. ${ }^{5 \mathrm{~d}}$ As shown in Figure 7 , the observed incorporation reached significantly higher levels in a broad range of solvents compared to the initial labeling result in DCM. In particular, chlorobenzene and fluorobenzene delivered the highest levels of labeling, affording excellent 93 and $91 \%$ incorporations, respectively. Additionally, the use of non-halogenated solvents such as di-iso-propyl ether, MTBE, diethyl ether, and toluene also provided high levels $(>70 \%)$ of deuterium incorporation.

Accordingly, chlorobenzene was chosen as the optimal solvent for this sulfone labeling process with catalyst 29. Not only did this medium allow for the best incorporation from the eleven solvents examined but also additional technical advantages were delivered, in that the higher boiling nature of chlorobenzene meant that cooling to $-78{ }^{\circ} \mathrm{C}$ could be avoided when exchanging the atmosphere within the reaction manifold from nitrogen to deuterium, thus simplifying the practical procedure. Notably, maintaining catalyst loadings at 5 mol \%, the reaction time could be reduced to $1 \mathrm{~h}$, with no drop in the observed isotope incorporation. ${ }^{15}$ These conditions were then applied to a broad range of aryl sulfones to establish the scope of our developed process (Scheme 3). A total of eighteen additional substrates were examined, encompassing a diverse range of sulfones with generally excellent deuterium incorporation effectiveness observed throughout the series. Both electron-donating and electron-withdrawing substituents 


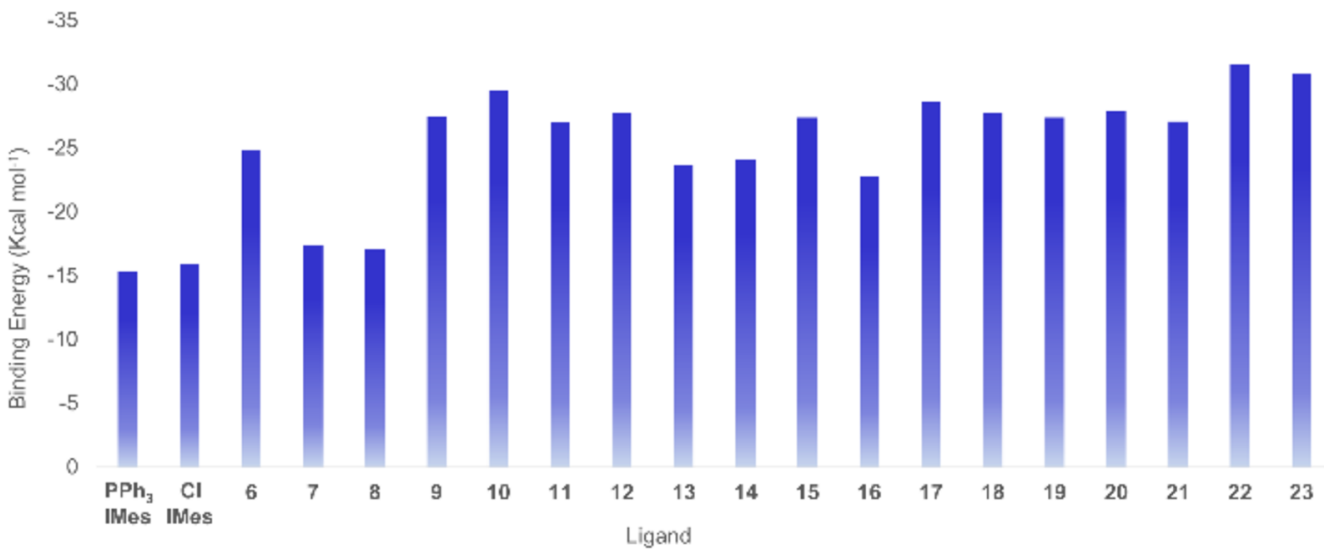

Figure 5. Calculated binding energies with sulfone 4a.
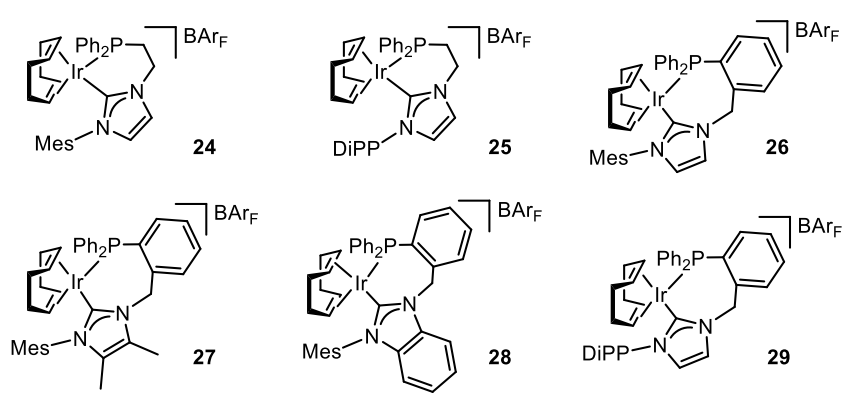

Figure 6. Summary of the targeted Iridium(I) precatalysts.

Table 1. Catalyst Screen $^{a}$<smiles>CS(=O)(=O)c1ccccc1</smiles><smiles>[2H]c1cccc([2H])c1S(C)(=O)=O</smiles>

entry

ry

4

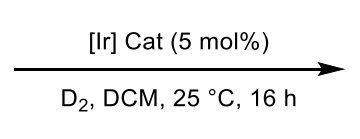

catalyst

$1 a$
$3 a$
24
25
26
27
28
29

${ }^{a}$ Reactions performed in triplicate.

in the ortho $(\mathbf{4 b}-\mathbf{4 d})$ and meta $(\mathbf{4 e}-\mathbf{4} \mathbf{h})$ positions of the aryl ring were well tolerated, leading to high levels of incorporation. Notably, meta-trifluoromethyl substrate $\mathbf{4} \mathbf{g}$ exhibits almost no incorporation at the considerably hindered position between both aryl substituents, but displays excellent levels of deuterium labeling at the less hindered position ortho to the sulfone. With less sterically encumbered meta substituents (4f and $4 \mathbf{h}$ ) both positions ortho to the sulfone are labeled to a high degree. A range of electronically distinct para-substituents are also well tolerated $(\mathbf{4 i}-\mathbf{4 l}, \mathbf{4 n})$. In the case of para-nitro substrate $4 \mathbf{m}$, this alternative directing group is shown to mildly outcompete the sulfone, but does not prevent an acceptable level of isotope incorporation through sulfonedirected HIE. Furthermore, restricting the orientation of the sulfone, as in cyclic substrate $4 \mathbf{4}$, did not result in a decrease in the excellent levels of incorporation generally observed. We
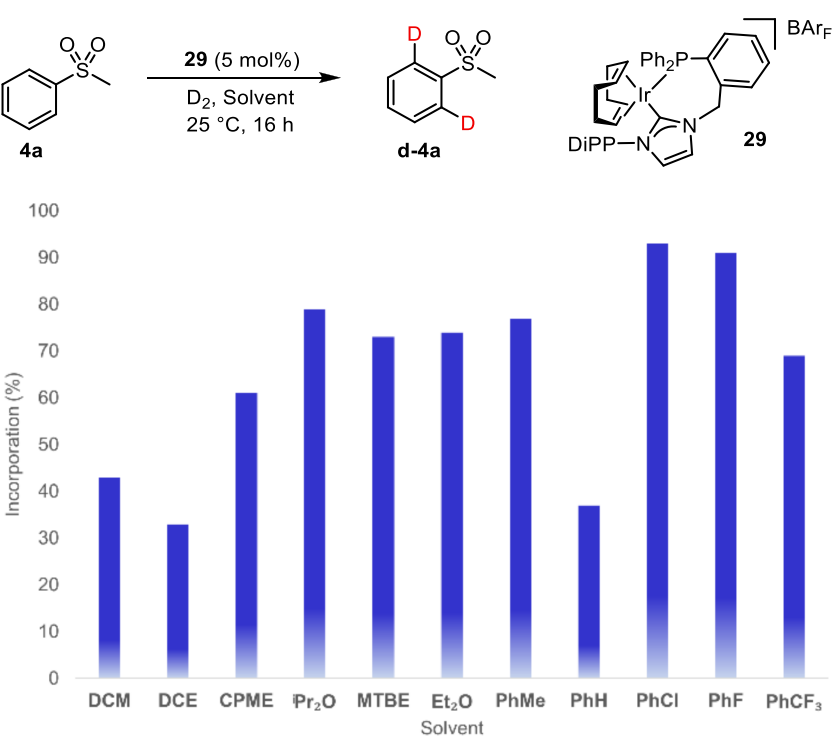

Figure 7. Solvent applicability in sulfone labeling. ${ }^{15}$

next turned our attention to the effects of increasing the steric bulk around the sulfone group, with substrates $4 \mathbf{p}-4 \mathbf{r}$. While a slight decrease in the levels of incorporated deuterium were observed in diphenyl sulfone $4 \mathrm{p}$ and iso-propyl phenyl sulfone $4 q$ (57 and 66\%, respectively), an excellent incorporation of $80 \%$ was observed with the bulky tert-butyl phenyl sulfone $4 \mathbf{r}$. We also investigated labeling of benzyl methyl sulfone $4 \mathbf{s}$, where the sulfone would direct labeling via a 6-membered metallacyclic intermediate (6-mmi), which is considerably less favored than the more common $5-\mathrm{mmi}^{5 \mathrm{c}}$ Nonetheless, moderate levels of incorporation were still observed in this more challenging substrate under these mild standard conditions with a low catalyst loading of $5 \mathrm{~mol} \%$.

To further expand the utility of our newly developed catalyst system, we investigated the effects of employing a reduced pressure of deuterium gas using a TRITEC manifold system, with these conditions more closely emulating those deployed for radiolabeling with tritium gas within a pharmaceutical industry setting. Following only minimal optimization of our standard conditions, ${ }^{15}$ we obtained high levels of labeling under these low-pressure conditions (Scheme 4). Employing phenyl methyl sulfone $4 a$, it was found that with a deuterium pressure of only $\sim 400$ mbar, a mildly elevated catalyst loading of $7.5 \mathrm{~mol} \%$ allowed for similar levels of deuterium 
Scheme 3. Scope of Aryl Sulfone Labeling

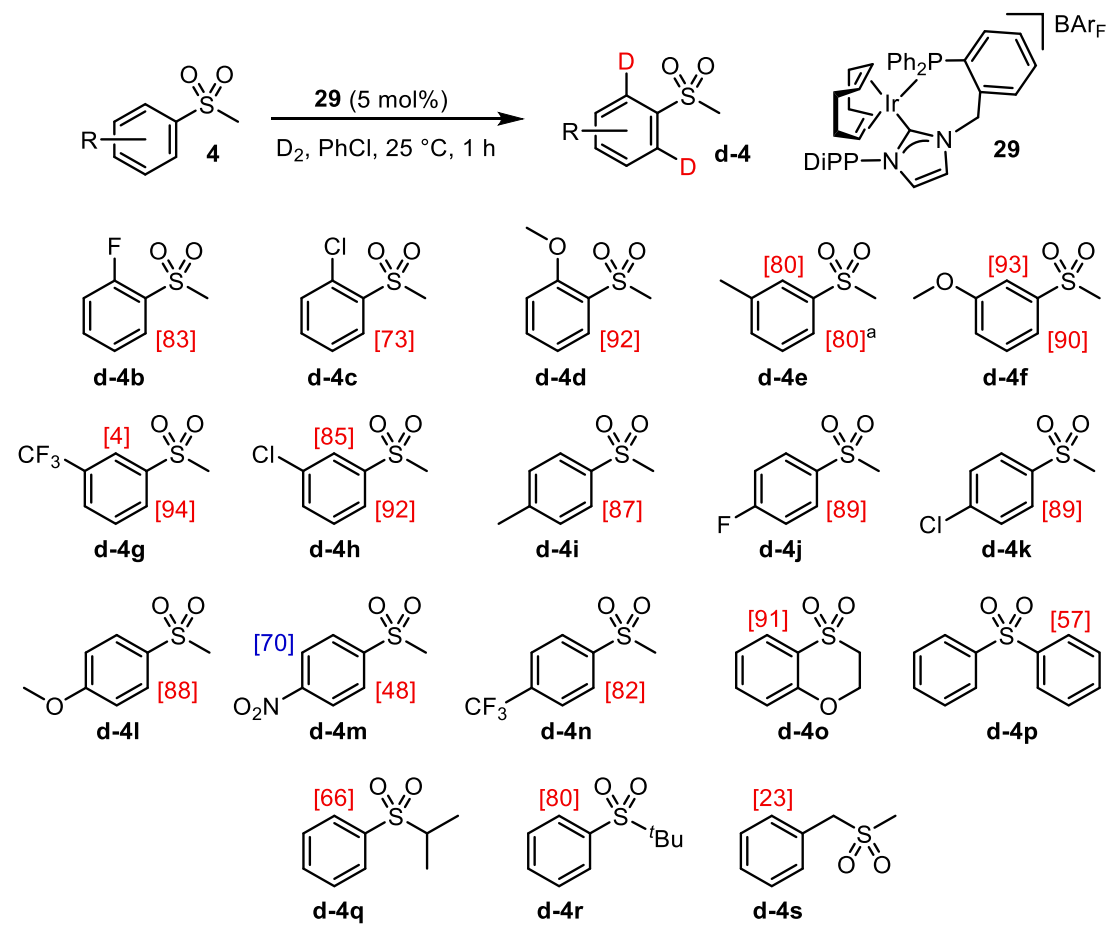

${ }^{a}$ Incorporation averaged across both positions.

Scheme 4. Reduced Pressure Deuterium and Tritium Labeling of Methyl Phenyl Sulfone 4a<smiles>[2H]c1cccc([2H])c1S(C)(=O)=O</smiles>
d-4a [90]
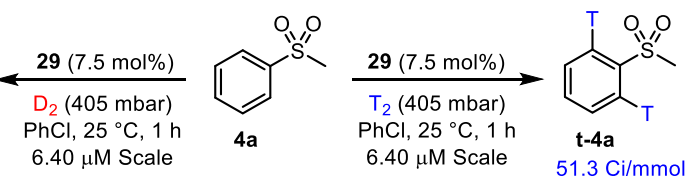

incorporation to the standard (non-TRITEC) laboratory setup. Notably, when employing the most active catalyst reported by Pfaltz and Muri, ${ }^{10 a}$ very low levels of labeling of this same substrate, $4 \mathrm{a}$, were observed when employing 1 atm of $\mathrm{D}_{2}$ for catalyst activation, ${ }^{15}$ as is routinely employed with our suite of $\operatorname{Ir}(\mathrm{I})$ catalysts, including 29. Indeed, the requirement for supraatmospheric catalyst activation with this previously reported system may present practical challenges when applying the methodology to low-pressure tritiations (vide infra).

With a successful reduced atmosphere protocol in hand using catalyst 29, the conditions were then applied to the tritium labeling of the same sulfone $4 a$. Exposure of $4 \mathbf{a}$ to 7.5 mol \% of precatalyst 29 under 405 mbar of tritium gas afforded t-4a with a high activity of $51.3 \mathrm{Ci} / \mathrm{mmol}$, corresponding to a tritium incorporation of $88 \%$ across both ortho positions. Additionally, the major mass ion of $[\mathrm{M}+4]$ confirmed that the sample had indeed been labeled with two units of tritium (Scheme 4).

Finally, to further demonstrate the power of our developed catalyst as applied to radiolabeling, as shown in Scheme 5 we targeted a tritium-labeled sample of the highly potent GPR119 agonist 30. ${ }^{16}$ Accordingly, benzylic bromide-containing sulfone $\mathbf{4 t}$ could be readily tritiated and alkylated in one pot to afford $\mathbf{t}$ 30 with excellent levels of radiolabel incorporation.

In conclusion, we have employed a computationally-guided, rational ligand design approach to target a series of iridium(I) NHC-P complexes for the directed HIE of aryl sulfones. The
Scheme 5. Tritium Labeling of GRP119 Agonist 30

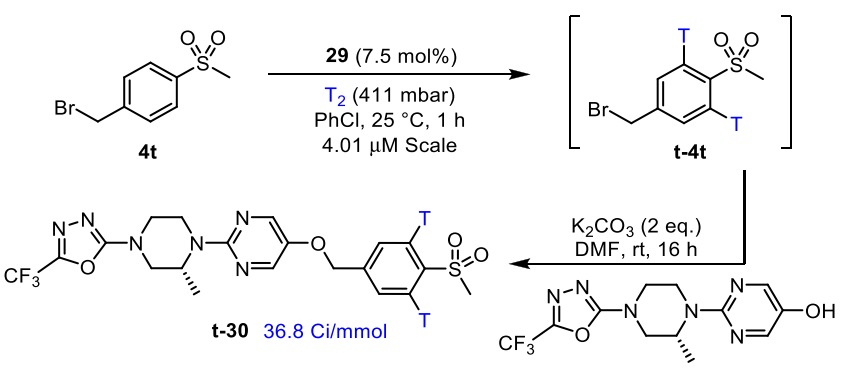

resulting optimal complex proved to be highly active in a range of solvents, and an extensive substrate scope has been established, with high levels of deuterium incorporation being exhibited across the series. Furthermore, the catalyst system has been shown to retain its activity when applied to the low-pressure labeling systems currently used extensively in the pharmaceutical industry. Finally, the emerging iridium(I) NHC-P catalyst has been applied to tritium labeling, furnishing a selectively tritiated sample of GPR119 agonist $\mathbf{t}-\mathbf{3 0}$ with high levels of specific activity. Our current studies are focused on extending our understanding of these catalytic systems in order to further refine our design process to encompass even more challenging substrates.

\section{ASSOCIATED CONTENT}

\section{Supporting Information}

The Supporting Information is available free of charge at https://pubs.acs.org/doi/10.1021/acscatal.0c03031.

Details of experimental procedures and computational methods (PDF) 


\section{AUTHOR INFORMATION}

\section{Corresponding Author}

William J. Kerr - Department of Pure and Applied Chemistry, University of Strathclyde, Glasgow G1 1XL, Scotland, U.K.; ๑ orcid.org/0000-0002-1332-785X; Email: w.kerr@ strath.ac.uk

\section{Authors}

Gary J. Knox - Department of Pure and Applied Chemistry, University of Strathclyde, Glasgow G1 1XL, Scotland, U.K.

Marc Reid - Department of Pure and Applied Chemistry, University of Strathclyde, Glasgow G1 IXL, Scotland, U.K.; ๑ orcid.org/0000-0003-4394-3132

Tell Tuttle - Department of Pure and Applied Chemistry, University of Strathclyde, Glasgow G1 1XL, Scotland, U.K.; ๑ orcid.org/0000-0003-2300-8921

Jonas Bergare - Early Chemical Development, Pharmaceutical Sciences, R\&D, Gothenburg SE-43183, Sweden

Ryan A. Bragg - Early Chemical Development, Pharmaceutical Sciences, R\&D, AstraZeneca, Cambridge CB2 OAA, U.K.

Complete contact information is available at:

https://pubs.acs.org/10.1021/acscatal.0c03031

\section{Notes}

The authors declare no competing financial interest.

\section{ACKNOWLEDGMENTS}

An EPSRC Industrial CASE PhD Studentship (G.J.K.; Grant Ref. EP/M507647/1) with additional support from AstraZeneca, and a Carnegie Trust Studentship (M.R.) are gratefully acknowledged. Mass spectrometry data were acquired at the EPSRC UK National Mass Spectrometry Facility at Swansea University.

\section{ABBREVIATIONS}

$\mathrm{BAr}_{\mathrm{F}} \quad$ tetrakis(3,5-bis(trifluoromethyl)phenyl)borate $\mathrm{Bn}$ benzyl

CPME cyclopentyl methyl ether

DCE 1,2-dichloroethane

DCM dichloromethane

DiPP 2,6-di-iso-propylphenyl

Mes 2,4,6-trimethylphenyl

MTBE methyl tert-butyl ether

NHC N-heterocyclic carbene

\section{REFERENCES}

(1) (a) Marathe, P. H.; Shyu, W. C.; Humphreys, W. G. The use of radiolabeled compounds for ADME studies in discovery and exploratory development. Curr. Pharm. Des. 2004, 10, 2991-3008. (b) Zhang, D.; Luo, G.; Ding, X.; Lu, C. Preclinical experimental models of drug metabolism and disposition in drug discovery and development. Acta. Pharm. Sin. B 2012, 2, 549-561. (c) Isin, E. M.; Elmore, C. S.; Nilsson, G. N.; Thompson, R. A.; Weidolf, L. Use of radiolabeled compounds in drug metabolism and pharmacokinetic studies. Chem. Res. Toxicol. 2012, 25, 532-542. (d) Penner, N.; Xu, L.; Prakash, C. Radiolabeled absorption, distribution, metabolism, and excretion studies in drug development: why, when and how? Chem. Res. Toxicol. 2012, 25, 513-531. (e) Atzrodt, J.; Derdau, V.; Kerr, W. J.; Reid, M. Deuterium- and tritium-labelled compounds: Applications in the life sciences. Angew. Chem., Int. Ed. 2018, 57, 1758-1784.

(2) (a) Chen, S.; Song, G.; Li, X. Chelation-assisted rhodium hydride-catalyzed regioselective $\mathrm{H} / \mathrm{D}$ exchange in arenes. Tetrahedron Lett. 2008, 49, 6929-6932. (b) Ma, S.; Villa, G.; Thuy-Boun, P. S.; Homs, A.; Yu, J.-Q. Palladium-catalyzed ortho-selective $\mathrm{C}-\mathrm{H}$ deuteration of arenes: evidence for superior reactivity of weakly coordinated palladacycles. Angew. Chem., Int. Ed. 2014, 53, 734-737. (c) Piola, L.; Fernández-Salas, J. A.; Manzini, S.; Nolan, S. P. Regioselective ruthenium catalyzed $\mathrm{H}-\mathrm{D}$ exchange using $\mathrm{D}_{2} \mathrm{O}$ as the deuterium source. Org. Biomol. Chem. 2014, 12, 8683-8688. (d) Atzrodt, J.; Derdau, V.; Kerr, W. J.; Reid, M. C-H functionalization for hydrogen isotope exchange. Angew. Chem., Int. Ed. 2018, 57, 3022-3047.

(3) (a) Crabtree, R. Iridium compounds in catalysis. Acc. Chem. Res. 1979, 12, 331-337. (b) Atzrodt, J.; Derdau, V.; Fey, T.; Zimmermann, J. The renaissance of $\mathrm{H} / \mathrm{D}$ exchange. Angew. Chem. Int. Ed. 2007, 46, 7744-7765. (c) Heys, J. R. Organoiridium complexes for hydrogen isotope exchange labeling. J. Labelled Compd. Radiopharm. 2007, 50, 770-778. (d) Nilsson, G. N.; Kerr, W. J. The development and use of novel iridium complexes as catalysts for ortho-directed hydrogen isotope exchange reactions. J. Labelled Compd. Radiopharm. 2010, 53, 662-667. (e) Salter, R. The development of iridium(I) phosphine systems for ortho-directed hydrogen isotope exchange. J. Labelled Compd. Radiopharm. 2010, 53, 645-657.

(4) (a) Filer, C. N. Direct metal-catalyzed tritiation of organic molecules. J. Labelled Compd. Radiopharm. 2010, 53, 739-744. (b) Modutlwa, N.; Maegawa, T.; Monguchi, Y.; Sajiki, H. Synthesis of deuterium-labelled drugs by hydrogen-deuterium (H-D) exchange using heterogenous catalysis. J. Labelled Compd. Radiopharm. 2010, 53, 686-692. (c) Shevchenko, V. P.; Nagaev, I. Y.; Myasoedov, N. F. The efficiency of solvent-free catalyst systems in the synthesis of tritium-labelled biologically active compounds. J. Labelled Compd. Radiopharm. 2010, 53, 693-703. (d) Hesk, D.; Lavey, C. F.; McNamara, P. Tritium labelling of pharmaceuticals by metal-catalysed exchange methods. J. Labelled Compd. Radiopharm. 2010, 53, 722730. (e) Allen, P. H.; Hickey, M. J.; Kingston, L. P.; Wilkinson, D. J. Metal-catalyzed isotopic exchange labelling: 30 years of experience in pharmaceuticals R\&D. J. Labelled Compd. Radiopharm. 2010, 53, 731-738. (f) Lockley, W. J. S.; McEwen, A.; Cooke, R. Tritium: a coming of age for drug discovery and development ADME studies. J. Labelled Compd. Radiopharm. 2012, 55, 235-257. (g) Elmore, C. S.; Bragg, R. A. Isotope chemistry: a useful tool in the drug discovery arsenal. Bioorg. Med. Chem. Lett. 2015, 25, 167-171.

(5) (a) Brown, J. A.; Irvine, S.; Kennedy, A. R.; Kerr, W. J.; Andersson, S.; Nilsson, G. N. Highly active iridium(I) complexes for catalytic hydrogen isotope exchange. Chem. Commun. 2008, 11151117. (b) Cochrane, A. R.; Idziak, C.; Kerr, W. J.; Mondal, B.; Paterson, L. C.; Tuttle, T.; Andersson, S.; Nilsson, G. N. Practically convenient and industrially-aligned methods for iridium-catalysed hydrogen isotope exchange processes. Org. Biomol. Chem. 2014, 12, 3598-3603. (c) Brown, J. A.; Cochrane, A. R.; Irvine, S.; Kerr, W. J.; Mondal, B.; Parkinson, J. A.; Paterson, L. C.; Reid, M.; Tuttle, T.; Andersson, S.; Nilsson, G. N. The synthesis of highly active iridium(I) complexes and their application in catalytic hydrogen isotope exchange. Adv. Synth. Catal. 2014, 356, 3551-3562. (d) Kennedy, A. R.; Kerr, W. J.; Moir, R.; Reid, M. Anion effects to deliver enhanced iridium catalysts for hydrogen isotope exchange processes. Org. Biomol. Chem. 2014, 12, 7927-7931. (e) Kerr, W. J.; Mudd, R. J.; Paterson, L. C.; Brown, J. A. Iridium(I)-catalyzed regioselective C$\mathrm{H}$ activation and hydrogen-isotope exchange of non-aromatic unsaturated functionality. Chem. - Eur. J. 2014, 20, 14604-14607. (f) Atzrodt, J.; Derdau, V.; Kerr, W. J.; Reid, M.; Rojahn, P.; Weck, R. Expanded applicability of iridium(I) $\mathrm{NHC} /$ phosphine catalysts in hydrogen isotope exchange processes with pharmaceutically-relevant heterocycles. Tetrahedron 2015, 71, 1924-1929. (g) Devlin, J.; Kerr, W. J.; Lindsay, D. M.; McCabe, T. J.; Reid, M.; Tuttle, T. Iridiumcatalysed ortho-directed deuterium labelling of aromatic esters - an experimental and theoretical study on directing group chemoselectivity. Molecules 2015, 20, 11676-11698. (h) Kerr, W. J.; Lindsay, D. M.; Reid, M.; Atzrodt, J.; Derdau, V.; Rojahn, P.; Weck, R. Iridium-catalysed ortho-H/D and $-\mathrm{H} / \mathrm{T}$ exchange under basic conditions: $\mathrm{C}-\mathrm{H}$ activation of unprotected tetrazoles. Chem. Commun. 2016, 52, 6669-6672. (i) Kerr, W. J.; Mudd, R. J.; 
Owens, P. K.; Reid, M.; Brown, J. A.; Campos, S. Hydrogen isotope exchange with highly active iridium(I) NHC/phosphine complexes: a comparative counterion study. J. Labelled Compd. Radiopharm. 2016 59, 601-603. (j) Kerr, W. J.; Lindsay, D. M.; Owens, P. K.; Reid, M.; Tuttle, T.; Campos, S. Site-selective deuteration of N-heterocycles via iridium-catalyzed hydrogen isotope exchange. ACS Catal. 2017, 7, $7182-7186$

(6) (a) Kerr, W. J.; Reid, M.; Tuttle, T. Iridium-catalyzed C-H activation and deuteration of primary sulfonamides: an experimental and computational study. ACS Catal. 2015, 5, 402-410. (b) Kerr, W. J.; Reid, M.; Tuttle, T. Iridium-catalyzed formyl-selective deuteration of aldehydes. Angew. Chem., Int. Ed. 2017, 56, 7808-7812.

(7) Sulfones in medicinal chemistry: (a) Feng, M.; Tang, B.; Liang, S. H.; Jiang, X. Sulfur containing scaffolds in drugs: synthesis and application in medicinal chemistry. Curr. Top. Med. Chem. 2016, 16, 1200-1216. (b) Bogolubsky, A. V.; Moroz, Y. S.; Mykhailiuk, P. K.; Ostapchuk, E. N.; Rudnichenko, A. V.; Dmytriv, Y. V.; Bondar, A. N.; Zaporozhets, O. A.; Pipko, S. E.; Doroschuk, R. A.; Babichenko, L. N.; Konovets, A. I.; Tolmachev, A. One-pot parallel synthesis of alkyl sulfines, sulfoxides, and sulfones. ACS Comb. Sci. 2015, 17, 348-354. (c) Scott, J. S.; Birch, A. M.; Brocklehurst, K. J.; Broo, A.; Brown, H. S.; Butlin, R. J.; Clarke, D. S.; Davidson, Ö.; Ertan, A.; Goldberg, K.; Groombridge, S. D.; Hudson, J. A.; Laber, D.; Leach, A. G.; MacFaul, P. A.; McKerrecher, D.; Pickup, A.; Schofield, P.; Svesson, P. H.; Sörme, P.; Teague, J. Use of small-molecule crystal structures to address solubility in a novel series of $\mathrm{G}$ protein coupled receptor 119 agonists: optimization of a lead and in vivo evaluation. J. Med. Chem. 2012, 55, 5361-5379.

(8) (a) Fourneau, E.; Tréfouöl, J.; Nitti, F.; Bovet, D. Action antistreptococcique des dérivés sulfurés organiues. CR Acad. Sci. 1937, 204, 1763-1766. (b) Cutler, R. A.; Stenger, R. J.; Suter, C. M. New antibacterial agents. 2-Acylamino-1-(4-hydrocarbonylsulfonylphenyl)1,3-propanediols and related compounds. J. Am. Chem. Soc. 1952, 74, 5475-5481. (c) Prasit, P.; Wang, Z.; Brideau, C.; Chan, C.-C.; Charleson, S.; Cromlish, W.; Ethier, D.; Evans, J. F.; FordHutchinson, A. W.; Gauthier, J. Y.; Gordon, R.; Guay, J.; Gresser, M.; Kargman, S.; Kennedy, B.; Leblanc, Y.; Léger, S.; Mancini, J.; O'Neill, G. P.; Ouellet, M.; Percival, M. D.; Perrier, H.; Riendeau, D.; Rodger, I.; Tagari, P.; Thérien, M.; Vickers, P.; Wong, E.; Xu, L.-J.; Young, R. N.; Zamboni, R. The discovery of refecoxib, [MK 996, VIOXX®, 4-(4'-methysulfonylphenyl)-3-phenyl-2(5H)-furanone], an orally active cyclooxygenase-2 inhibitor. Bioorg. Med. Chem. Lett. 1999, 9, 1773-1778. (d) Klaus, M. Tetrahydronapthalene and indane compounds useful as anti-tumor agents, US4,396,553 A1. August 1983, 2.

(9) See, for example Chen, D.; Xing, G.; Zhou, H. Sulfone promoted $\mathrm{Rh}$ (III)-catalyzed $\mathrm{C}-\mathrm{H}$ activation and base assisted 1,5-H shift strategy for the construction of seven-membered rings. Org. Chem. Front. 2015, 2, 947-950.

(10) (a) Parmentier, M.; Hartung, T.; Pfaltz, A.; Muri, D. Iridiumcatalyzed H/D exchange: Ligand complexes with improved efficiency and scope. Chem. - Eur. J. 2014, 20, 11496-11504. (b) Jess, K.; Derdau, V.; Weck, R.; Atzrodt, J.; Freytag, M.; Jones, P. G.; Tamm, M. Hydrogen isotope exchange iridium(I) complexes supported by imidazolin-2-imine P,N-ligands. Adv. Synth. Catal. 2017, 359, 629638.

(11) (a) Houk, K. N.; Cheong, P. H.-Y. Computational prediction of small-molecules catalysts. Nature 2008, 455, 309-313. (b) Poree, C.; Schoenebeck, F. A holy grail in chemistry: Computational catalyst design: Feasible or fiction. Acc. Chem. Res. 2017, 50, 605-608. (c) Bakr, B. W.; Sherrill, C. D. Analysis of transition state stabilization by non-covalent interactions in the Houk-List model of organocatalysed intermolecular aldol additions using functional-group symmetry-adapted perturbation theory. Phys. Chem. Chem. Phys. 2016, 18, 10297-10308.

(12) (a) Ruiz-Castillo, P.; Blackmond, D. G.; Buchwald, S. L. Rational ligand design for the arylation of hindered primary amines guided by reaction progress kinetic analysis. J. Am. Chem. Soc. 2015, 137, 3085-3092. (b) Gerosa, G. G.; Spanevello, R. A.; Suárez, A. G.;
Sarotti, A. M. Joint experimental, in silico, and NMR studies towards the rational design of iminium-based organocatalyst derived from renewable sources. J. Org. Chem. 2015, 80, 7626-7634. (c) Jindal, G.; Sunoj, R. B. Rational design of catalysts for asymmetric diamination reaction using transition state modeling. Org. Biomol. Chem. 2014, 12, 2745-2753.

(13) Boys, S. F.; Bernardi, F. The calculation of small molecular interactions by the differences of separate total energies. Some procedures with reduced errors. Mol. Phys. 1970, 19, 553-566.

(14) (a) Focken, T.; Raabe, G.; Bolm, C. Synthesis of iridium complexes with new planar chiral chelating phosphinyl-imidazolylidene ligands and their application in asymmetric hydrogenation. Tetrahedron: Asymmetry 2004, 15, 1693-1706. (b) Nanchen, S.; Pfaltz, A. Chiral phosphino- and (phosphinooxy)-substituted $N$ heterocyclic carbene ligands and their application in iridium-catalyzed asymmetric hydrogenation. Helv. Chim. Acta 2006, 89, 1559-1573. (c) Song, G.; Wang, X.; Li, Y.; Li, X. Iridium abnormal N-heterocyclic hydrides via highly selective $\mathrm{C}-\mathrm{H}$ activation. Organometallics 2008, 27, 1187-1192. (d) Wolf, J.; Labande, A.; Daran, J.-C.; Poli, R. Reactivity of phosphane-imidazolium salts towards $[\operatorname{Ir}(\mathrm{COD}) \mathrm{Cl}]_{2}$ : Preparation of new hydridoiridium(III) complexes bearing abnormal carbenes. Eur. J. Inorg. Chem. 2008, 2008, 3024-3030. (e) Wolf, J.; Labande, A.; Daran, J.-C.; Poli, R. Nickel(II) complexes with bifunctional phosphine-imidazolium ligands and their catalytic activity in the Kumada-Corriu coupling reaction. J. Organomet. Chem. 2006, 691, 433-443. For benzyl tethered systems: (f) Wang, A.-E.; Xie, J.H.; Wang, L.-X.; Zhou, Q.-L. Triaryl phosphine-functionalized Nheterocyclic carbene ligands for Heck reaction. Tetrahedron 2005, 61, 259-266. (g) Li, J.-Q.; Andersson, P. G. Room temperature and solvent-free iridium catalyzed selective alkylation of anilines with alcohols. Chem. Commun. 2013, 49, 6131-6133. (h) Miranda-Soto, V.; Grotjahn, D. B.; DiPasquale, A. G.; Rheingold, A. L. Imidazol-2-yl complexes of $\mathrm{Cp} * \mathrm{Ir}$ as bifunctional ambident reactants. J. Am. Chem. Soc. 2008, 130, 13200-13201. (i) Stylianides, N.; Danopoulos, A. A.; Tsoureas, N. ${ }^{1}$ Pyridine and phosphine functionalized $N$-heterocyclic carbene complexes of rhodium and iridium. J. Organomet. Chem. 2005, 690, 5948-5958. (j) Miranda-Soto, V.; Grotjahn, D. B.; Cooksy, A. L.; Golen, J. A.; Moore, C. E.; Rheingold, A. L. A labile and catalytically active imidazol-2-yl fragment system. Angew. Chem., Int. Ed. 2011, 50, 631-635. (k) Wheaton, C. A.; Bow, J.-P. J.; Stradiotto, M. New phosphine-functionalized NHC ligands: Discovery of an effective catalyst for the room-temperature amination of aryl chlorides with primary and secondary amines. Organometallics 2013, 32, 6148-6161. (1) Liu, X.; Braunstein, P. Remarkable inertness of copper(II) chelates of cyclen-based macrobiocycles with two trans- $N$ acetate arms. Inorg. Chem. 2013, 52, 7367-7379.

(15) See Supporting Information.

(16) Scott, J. S.; Bowker, S. S.; Brocklehurst, K. J.; Brown, H. S.; Clarke, D. S.; Easter, A.; Ertan, A.; Goldberg, K.; Hudson, J. A.; Kavanagh, S.; Laber, D.; Leach, A. G.; MacFaul, P. A.; Martin, E. A.; McKerrecher, D.; Schofield, P.; Svensson, P. H.; Teague, J. Circumventing seizure activity in a series of $G$ protein coupled receptor 119 (GPR119) agonists. J. Med. Chem. 2014, 57, 89848998. 